\title{
КОНЦЕПТУАЛЬНАЯ МОДЕЛЬ ПЛАНИРОВАНИЯ ПРОЦЕССА СНЕГОУБОРКИ
}

\author{
Т. Е. Григорьева, Н. А. Дегтярева, В. М. Дмитриев \\ Томский государственный университет систем управления и радиоэлектроники, \\ Томский филиал Российской академии народного хозяйства и государственной службъ \\ при Президенте Российской Федерации
}

\section{Поступила в редакцию 30.10.2018 г.}

\begin{abstract}
Аннотация. В данной статье рассматривается проблема планирования процесса снегоуборки, недоработки которой приводят к увеличению «пробок» на дорогах, числа дорожно-транспортных происшествий. Для осуществления планирования процесса снегоуборки в статье предлагается использовать имитационное моделирование, позволяющее «проиграть» планируемые процессы на моделях, определить «узкие места», недоработки, погрешности системы и т. д. Предлагаемая концептуальная модель планирования процесса снегоуборки позволит сформировать информационную модель процессов; разработать имитационную модель, включающую в себя физическую, дискретно-событийную и экономическую модель объекта и на завершающем этапе, на основе полученных варьируемых параметров модели сформировать управленческое решение в виде плана снегоуборочных работ.
\end{abstract}

Ключевые слова: этапы снегоуборки, Спецавтохозяйство, факторы снегоуборки, диаграмма Исикавы, имитационное моделирование, планирование процесса снегоуборки, принятие управленческих решений.

Annotation. The article deals with the problem of planning the process of snow removal, the flaws in which lead to an increase in traffic jams and the number of road accidents. To plan the process of snow removal, the article proposes to use simulation modeling, which allows you to "lose" the planned processes on the models, identify bottlenecks, shortcomings, system errors, etc. The proposed conceptual model of planning for the snow removal process will allow to form an information model of the processes and to develop a simulation model that includes the physical, discrete event and economic model of the object. At the final stage, the management decision is formed in the form of the plan of snow-removal based on the obtained variable parameters of the model.

Keywords: stages of snow removal, Spetsavtokhozyaystvo, factors of snow removal, Ishikawa chart, simulation modeling, planning of the snow removal process, making management decisions.

\section{ВВЕДЕНИЕ}

В зимнее время года коммунальные хозяйства городов испытывают максимальные нагрузки, связанные с зимним содержанием дорог.

Под зимним содержанием автомобильных дорог подразумевают комплекс мероприятий по обеспечению безопасного и бесперебойного движения транспорта на автомобиль2018

(ㄱ Григорьева Т. Е., Дегтярева Н. А., Дмитриев В. М., ных дорогах и искусственных сооружениях в зимний период, включающий защиту автомобильных дорог от снежных заносов и лавин, очистку от снега, предупреждение и устранение зимней скользкости и наледей [1].

В данной статье рассматривается процесс снегоуборки, включающий в себя не только уборку снега с проезжей части дороги, но и вывозку снега на полигон.

Некачественное содержание дорог зимой приводит к образованию «пробок» на дорогах, а также провоцирует увеличение числа дорожно-транспортных происшествий. 
По причине особенностей климата и географического положения России, а в частности Сибири, с наступлением холодов остро становится проблема снегоуборки.

Анализируя новостную ленту, мнения жителей, звонки круглосуточной «горячей линии» можно сделать вывод, что проблема снегоуборки актуальна во многих городах, в том числе и в городах Сибири [2-4].

Что касается города Томска, то за последние несколько лет среднегодовое количество осадков в Томской области увеличилось. По данным Гидрометцентра снежный покров увеличился с 6174 см до 11269 см [5]. Так зимой 2016-2017 г. в Томске уровень снега вдвое превысил годовую норму, высота снежного покрова в Томской области составила 91 сантиметр при норме в 50 сантиметров, в связи с чем актуализируется потребность в более качественной организации уборки и вывозки снега.

Механизированную уборку городских дорог осуществляют Спецавтохозяйства (в данном случае УМП «Спецавтохозяйство» г. Томска). Анализируя информационные источники, зимой 2016-2017 года УМП «Спецавтохозяйство» (СAX) с уборкой города не справлялись, так только в администрацию Ленинского района томичи активно жаловались на плохое качество уборки снега и за новогодние каникулы поступило 200 таких обращений [6]. Кроме того, 16 января 2017г. была опубликована петиция с обращением к президенту страны с просьбой обратить внимание на ситуацию с уборкой снега.

Управление любыми организационными системами должно стремиться, скорее, предупреждать нарушения в работе системы, чем исправлять их последствия через актуализацию функций. Основными функциями управления в организационных системах являются: планирование, мотивация, организация, контроль и т. д. Среди вышеперечисленных функций одной из самых важных является планирование.

Планирование является динамической функцией, которая используется для создания прочного фундамента для остальных видов управленческой деятельности. Цель функции планирования состоит в создании взаимообусловленной системы принятия решений, позволяющей улучшить работу организации. Планирование позволяет обеспечить организационные предпосылки для принятия эффективных решений на предприятии [7].

Так, благодаря планированию УМП «Спецавтохозяйство» сможет не только заблаговременно оценить количество требуемых ресурсов, т.е. определить потребность в снегоуборочной технике и кадровом составе, но и оценить предполагаемые финансовые затраты предприятия, определить риски предприятия, организовать процессы снегоуборки, согласно выделенному ресурсу техники, иными словами при планировании должны быть учтены оперативные параметры, например, погодные условия малоснежной и многоснежной зим; рациональное распределение и количество внутренних и внешних ресурсов и т. д.

Анализ современного состояния исследований в области планирования зимнего содержания дорог показывает, что в работах, посвященных выбранному направлению исследований в основном освещаются этапы планирования и прогнозирования потребляемых ресурсов [8] и финансовых затрат [9]. В исследованиях явно не прослеживается анализ процессов, функционирующих в организационной системе «Спецавтохозяйство» $(\mathrm{CAX})$. Хотя для оценки и прогноза финансовых затрат, учитывающих требования законодательно-нормативных документов наиболее значимым является планирование процессов деятельности CAX, например, процессов механизированного сгребания и подметания снега с проезжей части улиц, формирования снежного вала и т. д., что лежит в основе определения себестоимости затрат на зимнее содержание дорог.

Таким образом, целью данной статьи является разработка концептуальной модели планирования процесса снегоуборки, учитывающая не только ресурсы и затраты, но и неуправляемые факторы (например, погодные условия) и процессы, протекающие в УМП «Спецавтохозяйство». 


\section{T. Е. Григорьева, Н. А. Дегтярева, В. М. Дмитриев}

\section{ХАРАКТЕРИСТИКА ПРОЦЕССОВ ЗИМНЕЙ УБОРКИ}

На рис. 1 представлены процессы зимней уборки городских территорий, в которых выделяют 5 этапов:

1) механизированная посыпка проезжей части противогололедными материалами это процесс, при котором пескоразбрасыватели обрабатывают проезжую часть противогололедными материалами.

2) механизированное сгребание и подметание снега с проезжей части улиц - это процесс, во время которого снегоуборочная техника избавляется от излишков снега, сталкивая его на обочину. Сроки уборки: дороги I категории - 4 часа после окончания снегопада, II категории - 8 часов, III категории 12 часов;

3) формирование снежного вала - это процесс, при котором снег, очищаемый с проезжей части сдвигается в лотковую часть дороги для временного складирования снежной массы.

4) механизированная погрузка снега - это процесс, при котором подготовленный снег сгружается в самосвалы. Сроки уборки: дороги I категории - 48 часов, II категории - 60 часов, III категории - 96 часов.

5) вывозка снега самосвалами - это процесс, при котором груженый снег вывозится на полигон самосвалами.

Практика показывает, что этапы технологического процесса снегоуборки представляют собой взаимосвязанные между собой подпроцессы. Так при прохождении технологического процесса снегоуборки изменяется изначально зафиксированный объем снега.
Работы по снегоочистке дорог делят на объемные, для которых можно определить объем снега, подлежащий уборке, и безобъемные, для которых объем убираемого снега определить нельзя. К безобъемным работам относится патрульная очистка дорог (2 этап). Все остальные виды снегоочистительных дорог расчистка снежных заносов, удаление снежных валов, расчистка лавинных завалов - относятся к объемным работам [10].

При посыпке проезжей части противогололедными материалами (1 этап) увеличивается плотность снега в связи с тем, что при соприкосновении его с противогололедными материалами он превращается в жидкий раствор, что соответственно вызывает уменьшение его объема. При добавлении реагентов в соотношении $1 / 250$ массы снега его плотность увеличивается на 6-10\%. Наиболее увеличивается плотность снега, если снег с добавлением реагентов подвергается перемешиванию и уплотнению под воздействием колес транспортных средств. Так, при плотности потока автомобилей примерно 120 машин в час плотность снега может увеличиваться до $30 \%$.

На этапе формирования снежного вала (3 этап) снег уплотняется, причем коэффициент уплотнения свежевыпавшего снега при уборке принимают равный 3-3,5.

На этапе механизированной погрузки (4 этап) процесса снегоуборки, от объема снега зависит количество самосвалов, требуемых для уборки.

Рассмотрев этапы и подпроцессы можно сделать вывод, что весь технологический процесс снегоуборки состоит из взаимосвязанных между собой подпроцессов, которые

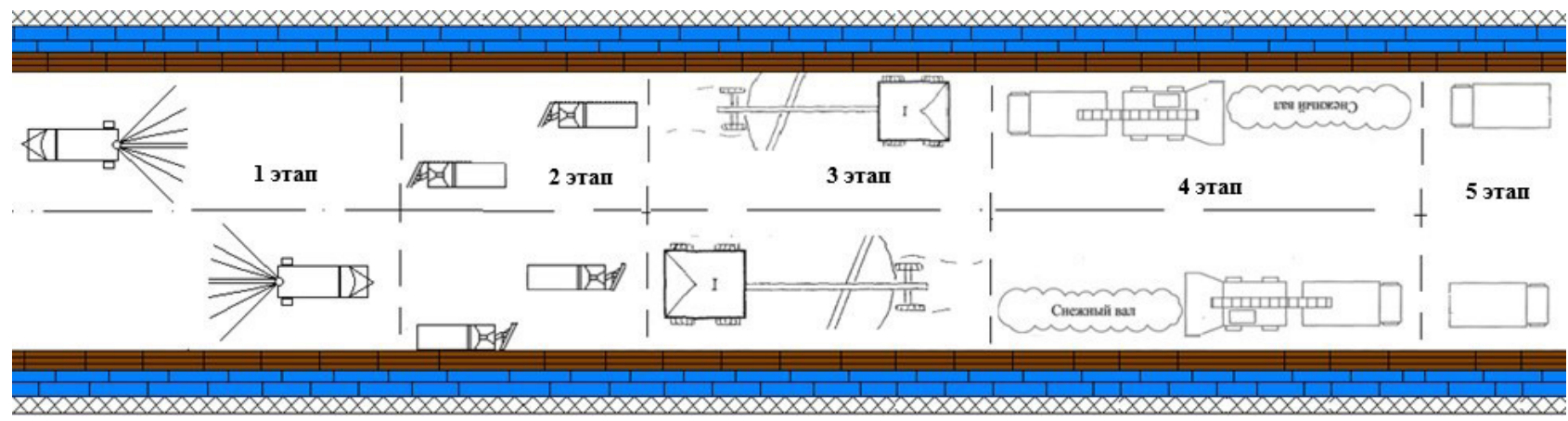

Рис. 1. Этапы зимней уборки 
нужно рассматривать как единое целое для эффективного планирования и использования ресурсов, таких как снегоуборочная техника, кадровый состав, время и, конечно, же, финансовые затраты.

\section{ПОСТАНОВКА ПРОБЛЕМЫ ИССЛЕДОВАНИЯ}

Деятельность САХа должна соответствовать требованиям ГОСТов, инструкций, постановлений и т. д. В соответствии с ГОСТами, инструкциями и т. д. актуальными задачами и функциями «Спецавтохозяйств» в зимних условиях являются:

- содержание в постоянной исправности и обеспечение эффективного использования средств, предназначенных для эксплуатации автомобильных дорог;

- организация ежегодного планирования зимних работ с использованием специализированных метеорологических прогнозов и рекомендаций по действиям дорожно-эксплуатационных служб;

- обеспечение контроля за сохранностью автомобильных дорог и дорожных сооружений в зимних условиях с использованием технических средств [1].

Однако согласно жалобам от населения, оповещениям средств массовой информации уборка и вывозка снега не соответствуют установленным требованиям. Например, согласно Постановлению Администрации города Томска от 14 октября 2014 года № 1035 (с изменениями на 22 сентября 2017 года) «О Порядке организации и проведения ремонта и содержания автомобильных дорог местного значения муниципального образования "Город Томск"» уборка проезжей части от снега должна быть завершена в следующие сроки: для улиц I категории - 4 часа, для улиц II категории - 8 часов, для улиц III категории - 12 часов [11].

Более того, на сегодняшний день Правительство совместно с Министерством транспорта и МВД разработали новые правила уборки проезжих частей и улиц, согласно которым на покрытии проезжей части дорог и улиц не допускаются наличие снега и зим- ней скользкости. Поверхность должна быть полностью убрана от рыхлого или талого снега в течение 3-12 часов, от наледи, гололеда, наката от 4-12 часов в зависимости от категории дорог. Это значит, что, проезжая часть в городах со следующей зимы должна быть полностью очищена от снега и любых других снежно-ледовых отложений [12].

Исходя из задач и реального состояния процесса уборки и вывозки снега, видно, что деятельность САХа в настоящее время не соответствует установленным стандартам, а с введением новых требований повысится вероятность отклонения от принятого ГОСТа, что повлечет за собой штрафы и жалобы населения.

Таким образом, проблема зимнего содержания дорог заключается в несвоевременной уборке и вывозке снега.

\section{ПРИЧИННО-СЛЕДСТВЕННЫЙ АНАЛИЗ ПОСТАВЛЕННОЙ ПРОБЛЕМЫ}

В процессе осмысления поставленной проблемы необходимо установить совокупность факторов, влияющих на конечный результат, допустимые отклонения, данные о ресурсах. Для того чтобы определить факторы, влияющие на поставленную проблему, воспользуемся причинно-следственной диаграммой Исикавы.

Диаграмма Исикавы представляет собой средство графического упорядочения факторов, причем главным ее достоинством является то, что она дает наглядное представление не только о тех факторах, которые влияют на изучаемый объект, но и о причинно-следственных связях этих факторов. Более того, актуализируется вопрос доминантных и второстепенных факторов, соподчиненности причин проблемы [13].

На рис. 2 представлен причинно-следственный анализ процесса несвоевременной уборки и вывозки снега.

После построения диаграммы Исикавы необходимо проранжировать выявленные причины в порядке важности. Здесь можно воспользоваться правилом Парето: устранение 20 \% причин может решить проблему на 


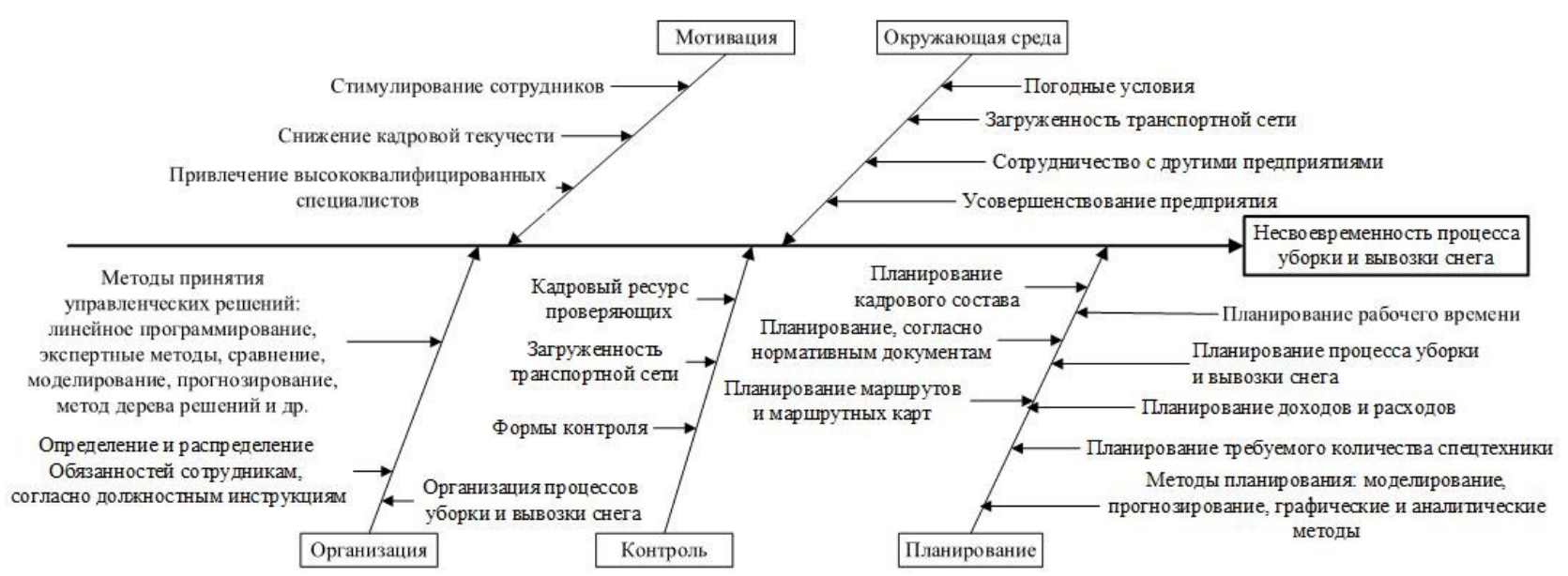

Рис. 2. Причинно-следственный анализ процесса несвоевременной уборки и вывозки снега

$80 \%$. В данном случае, если рассмотреть по количеству блоков (5 шт.), то для устранения 20 \% причин необходимо реализовать 1 блок.

Причинно-следственный анализ показывает, что этап планирования является наиболее значимым фактором, недоработка которого приводит к несвоевременной уборке и вывозке снега. Более того, он обеспечивает основу для принятия интегрированных решений. Процессы планирования и принятия решений неотделимы друг от друга. Если решение - это выбор одного из альтернативных путей, но само по себе оно не является планом, так как не всегда связано с действием или сроком его исполнения то планирование - это процесс, с помощью которого система использует свои возможности для изменения внешних и внутренних условий. Иными словами, без планирования система оставалась бы неизменной во времени и не могла бы развиваться и добиваться нового состояния равновесия [7].

На этапе планирования могут применяться разные методы, в данной статье для осуществления планирования процесса снегоуборки предлагается использовать один из методов управленческой методологии это имитационное моделирование. Оно позволяет «проиграть» планируемые процессы на моделях, определить "узкие места», недоработки и погрешности системы. По результатам моделирования на основе полученных «проигранных» альтернатив предоставляется возможность выбора наилучшей.

\section{КОНЦЕПТУАЛЬНАЯ МОДЕЛЬ ПЛАНИРОВАНИЯ ПРОЦЕССА СНЕГОУБОРКИ}

Методологически принцип имитационного моделирования является универсальным и позволяет выявить в модели проблемные участки, «узкие места», тем самым усовершенствовать процессы планирования и организации.

На рис. 3 представлена концептуальная модель планирования процесса снегоуборки.

Для эффективного управления зимней уборкой улично-дорожных сетей (УДС) огромную роль играет информация и ее упорядоченное представление в виде информационной модели. Для построения информационной модели формируется структурно упорядоченная база данных (БД) требуемых параметров. Причем эффективное управление над зимней уборкой УДС зависит от качества, точности и актуальности собранной информации.

Предлагаемая информационная модель основывается на следующих данных: погодные условия, о которых САХ осведомляет Гидрометцентр; информационные источники (например, информация о пробках на дорогах); перечень улиц, закрепленных за САХом, который устанавливается условиями муниципального контракта, заключенного между Спецавтохозяйством и городской администрацией; ресурсы предприятия, включающие в себя кадровый состав, финансовые затраты и спецтехнику. Помимо этого, в 
Конщептуальная модель планирования процесса снегоуборки

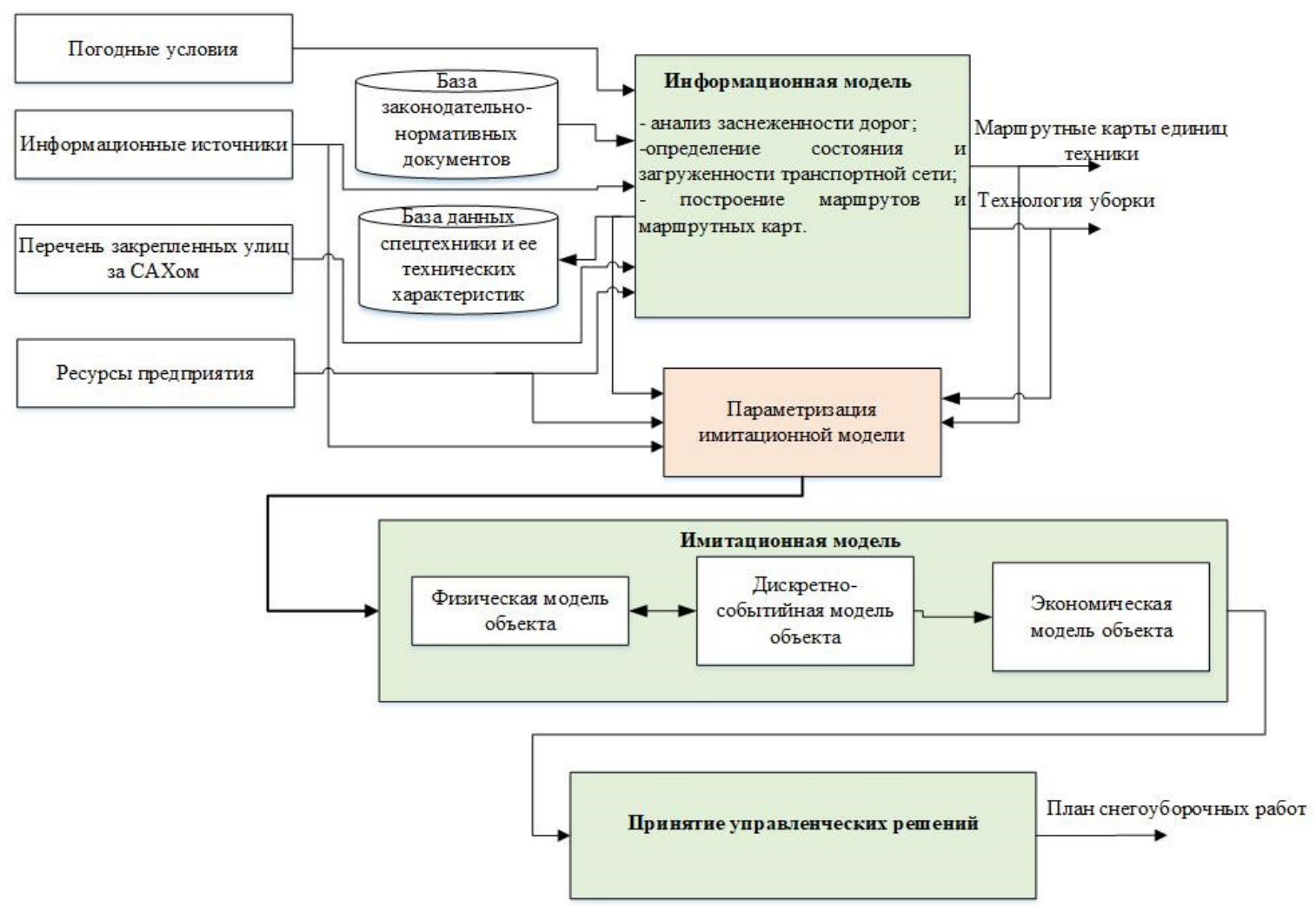

Рис. 3. Концептуальная модель планирования процесса снегоуборки

информационной модели важно учитывать законодательно-нормативные документы, peгламентирующие процессы уборки и технические характеристики снегоуборочной техники, которая в дальнейшем может привести к увеличению финансовых затрат. Результатом информационной модели являются сформированная технология уборки и построенные маршрутные карты каждой единицы снегоуборочной техники.

В дальнейшем с помощью входных и выходных данных информационной модели параметризуется имитационная модель уборки УДС.

В имитационной модели уборки под объектом понимается единица снегоуборочной техники, например, самосвал, грейдер и т. д. Она состоит из трёх взаимосвязанных составляющих:

Физическая модель объекта, которая отражает физическое поведение исследуемого объекта с подключенными к нему моделями измерительных устройств, осуществляющих генерацию внутренних событий компонента и исполнительных, формирующих варьируемые параметры объекта [14].
Дискретно-событийная модель объекта, формирующая функциональную модель объекта исследования, которая описывает ответную реакцию объекта на происходящие в модели события с выработкой управляющих воздействий на нее и с учетом заданных входных данных, сформированных пользователем [15].

В результате физической и дискретно-событийной моделей определяется продолжительность каждой технологической операции процесса снегоуборки. Затем продолжительность технологических операций учитывается при построении экономической модели.

Экономическая модель объекта позволяет оценить себестоимость работ зимнего содержания дорог. Общая себестоимость включает в себя: затраты на эксплуатацию метеорологического обеспечения, зарплата рабочих, себестоимость эксплуатации машин, себестоимость стоимости материалов, затраты на эксплуатацию снежных свалок.

Одним из основных преимуществ имитационного моделирования как метода изучения и анализа различных процессов является то, что оно позволяет без существенных 


\section{Т. Е. Григорьева, Н. А. Дегтярева, В. М. Дмитриев}

затрат спрогнозировать влияние внедряемых изменений, оценить предполагаемую выгоду, либо возможный ущерб. Кроме того, имитационное моделирование позволяет провести серию экспериментов, осуществляющихся варьированием параметров модели.

На завершающем этапе, на основе полученных варьируемых параметров модели необходимо сформировать управленческое решение. Для принятия управленческого решения существуют различные методы, такие как линейное программирование, экспертные методы, сравнение, моделирование, прогнозирование, метод дерева решений и др. Согласно вышеперечисленным методам необходимо определить область проблемы, выявить факторы, влияющие на ее решение, подобрать приемы, которые позволят сформулировать или поставить задачу таким образом, чтобы решение было выполнено.

Для определения экономической эффективности процесса снегоуборки применяется метод сравнения, позволяющий обосновать целесообразность принимаемого решения.

Зимнее содержание дорог экономически целесообразно при условии (1):

$$
P<\Pi,
$$

где $P=P_{1} \cup P_{2} \cup \ldots \cup P_{k}-$ стоимость зимнего содержания дорог, согласно оцениваемым этапам уборки $P_{1}, P_{2}, \ldots, P_{k} ; \Pi=\Pi_{1} \cup \Pi_{2} \cup$ $\ldots \cup \Pi_{k}-$ совокупность потерь, вызванных отсутствием зимнего содержания дорог [10].

В результате имитационного моделирования будет рассчитана себестоимость моделируемых процессов снегоуборки. Для определения экономической эффективности потребуется стоимость моделируемых процессов снегоуборки, которая складывается из себестоимости процессов и процента рентабельности. В итоге, чтобы оценить экономическую целесообразность требуется оценить потери, связанные с зимним содержанием городских автомобильных дорог, например, потери из-за роста ДТП; потери ущерба от загрязнения окружающей среды противогололедными материалами; потери от увеличения себестоимости автомобильных перевозок; потери времени из-за снижения скорости движения автомобильного транспорта в те- чение зимнего периода, потери времени из-за перепробега автомобилей, потери, вызванные нарушением организации дорожного движения из-за снегоочистки и т. д.

\section{ЗАКЛЮЧЕНИЕ}

Предлагаемая концептуальная модель позволит эффективно и заблаговременно планировать процессы уборки и вывозки снега, а также принимать обоснованные решения, анализируя различные варианты альтернатив, полученных при проигрывании их на модели.

В случае заблаговременного планирования CAX сможет соответствовать установленным требованиям, вследствие чего повысится уровень социально-экономического эффекта [16-17], под которым подразумеваются: экономия эксплуатационных затрат снегоуборочной техники, снижение потерь времени транспортным потоком и пассажирами, снижение ущерба от дорожно-транспортных происшествий, сокращение ущерба от повышенного выброса вредных веществ в атмосферу при движении автомобилей на пониженных скоростях.

Представленная модель планирования процессов снегоуборки является универсальной. В данной статье она рассматривается именно для уборки и вывозки снега, но при изменении входных параметров и конкретизации этапов модель может быть перестроена для разных видов деятельности САХ, например, для вывоза мусора, для поливки улиц и т. д.

Таким образом, имитационное моделирование является способом решения вызовов, которые существуют в настоящее время в городе:

1. Участие в проекте «Создание Центра компетенций по вопросам городской среды Томской области» по совершенствованию городской среды Томской области [18];

2. Продвижение стратегии социальноэкономического развития муниципального образования «Город Томск» до 2030 года, в которой одним из направлений является развитие комфортной городской среды. Од- 
ной из задач данного направления является совершенствование улично-дорожной сети, обеспечивающей безопасность движения и рациональное распределение транспортных потоков [19].

\section{СПИСОК ЛИТЕРАТУРЫ}

1. ОДМ 218.8.002-2010. Методические рекомендации по зимнему содержанию автомобильных дорог с использованием специализированной гидрометеорологической информации (для опытного применения). - Введ. 2010-07-01 - Москва, 2010. - 52 с.

2. Снег пойдет: эксперты оценили, грозят ли дорогам Новосибирска проблемы. - Режим доступа: https://nsk.rbc.ru/nsk/18/10/201 7/59e5deae9a7947917eb83fff (Дата обращения: 14.06.2018).

3. Хроника уборки снега в Красноярске: техники хватило, но распределили ее неправильно. - Режим доступа: https://www.krsk. kp.ru/daily/26762/3794058/ (Дата обращения: 11.06.2018).

4. Референдум, сообщения СМИ. - Режим доступа: http://www.referendum.tomsk.ru/ topic.phtml?id=4317\&view=news (Дата обращения: 14.06.2018).

5. Архив погоды в Томске. - Режим доступа: https://rp5.ru/Архив_погоды_в_Томске. (Дата обращения: 09.06.2018).

6. Снег на голову: как власти Томска «вывозят» проблему. - Режим доступа: https:// www.riatomsk.ru/article/20170111/uborkasnega-tomsk-reshenie-problemi/ (Дата обращения: 14.06.2018).

7. Лаврушина, Е. Г. Теория систем и системный анализ: учебный комплекс / Е. Г. Лаврушина, Н. Л. Слугина. - Владивосток : Изд-во ВГУЭС, 2007. - 168 с.

8. Белоусов, B. Е. Управление ресурсами при зимнем содержании региональной сети автомобильных дорог/ В. Е. Белоусов, Т. В. Самодурова, В. Н. Шарапова // Вестник ВГТУ. - 2010. - №7. С. 51-55.

9. Нехай, К. Применение новых технологий при планировании затрат на содержание автомобильных дорог/ К. Нехай, А. Лебедь,
А. Глотов // Транспорт Российской Федерации. -2006. - №6 (6). С. 20-22.

10. Зимнее содержание автомобильных дорог / Г. В. Бялобжеский, [и др.]; под ред. А. К. Дюнина. - 2-е изд., перераб. и доп. - М. : Транспорт, 1983. - 197 с.

11. Порядок организации и проведения ремонта и содержания автомобильных дорог местного значения муниципального образования “Город Томск”. - Введ. 2014-10-14. (с изменениями на 22 сентября 2017 года). Томск: Постановление Администрации города Томска, 2014. - 14 с.

12. В России ужесточают требования к содержанию дорог. - Режим доступа: https://roszimdor.ru/press-tsentr/publikaciiehkspertov/v-rossii-uzhestochayut-trebovaniyak-soderzhaniyu-dorog/ (Дата обращения: 06.06.2018).

13. Кудж, С. А. Закономерности информационного поля: монография / С. А. Кудж, В. Я. Цветков. - Москва : МАКС Пресс, 2017. $77 \mathrm{c}$.

14. Дмитриев, В. М. Компьютерное моделирование процесса уборки и вывоза снега / В. М. Дмитриев, Т. Е. Григорьева // Природные и интеллектуальные ресурсы Сибири (СИБ-РЕСУРС-21-2015): доклады 21-й Международной научно-практической конференции (Томск, 17-18 ноября 2015г.). - Томск : САН ВШ; В-Спектр, 2015. - С. 45-48.

15. Григорьева Т. Е. Дискретно-событийное моделирование в СМ МАРС для курса «Системы массового обслуживания» / Т. Е. Григорьева // Доклады Томского государственного университета систем управления и радиоэлектроники. -2014. - №1 (31). - С. 152155.

16. Исследование влияния инфраструктуры городского хозяйства на региональное социально-экономическое развитие / Е. В. Уфимцева [и др.] // Региональная экономика: теория и практика. -2017. - Т. 15, № 2 (437). - С. 237-253.

17. Formation of methodological approaches to assessing the implementation efficiency of budget programs of municipalities: a comparative aspect / Ufimtseva E.V. [and etc.] // Espacios. -2017. - book 38, № 49. - P. 21. 
18. Стратегическая сессия дизайн-мышления по созданию регионального центра компетенций по вопросам городской среды в Томской области. - Режим доступа: https:// leader-id.ru/event/9047/ (Дата обращения: 20.06.2018).

Григорьева Татьяна Евгеньевна - аспирантка кафедры компьютерных систем в управлении и проектировании, Томский государственный университет систем управления и радиоэлектроники.

Тел.: +7-3822-41-39-15, +7-952-181-63-55

E-mail: tanya_grig_1991@mail.ru

Дегтярева Наталия Алексеевна - канд. истор. наук, доцент кафедры компьютерных систем в управлении и проектировании, Томский государственный университет систем управления и радиоэлектроники, Томский филиал Российской академии народного хозяйства и государственной службы при Президенте Российской Федерации.

Тел.: +7-3822-41-39-15, +7-3822-51-58-95

E-mail: zxasqw@scalpnet.ru

Дмитриев Вячеслав Михайлович - д-р техн. наук, профессор кафедры компьютерных систем в управлении и проектировании, Томский государственный университет систем управления и радиоэлектроники.

Тел.: +7-3822-41-39-15

E-mail:dmitriewvm@gmail.com
19. Стратегия социально-экономического развития Томской области до 2030 года. - Режим доступа: https://tomsk.gov.ru/ctrategijasotsialno-ekonomicheskogo-razvitija-tomskojoblasti-do-2030-goda (Дата обращения: 20.06.2018).

Grigorieva Tatyana Evgenyevna - PhD student of the Department of Computer Control and Design Systems, Tomsk State University of Control Systems and Radioelectronics.

Tel.: +7-3822-41-39-15, +7-952-181-63-55

E-mail: tanya_grig_1991@mail.ru

Degtyareva Natalia Alekseevna - Candidate of Historical Sciences, Assistant Professor of the Department of Computer Control and Design Systems, Tomsk State University of Control Systems and Radioelectronics, Tomsk branch of the Russian Academy of National Economy and Public Administration under the President of the Russian Federation.

Tel.: +7-3822-41-39-15, +7-3822-51-58-95

E-mail: zxasqw@scalpnet.ru

Dmitriev Vyacheslav Mikhaylovich - Doctor of Technical Sciences, professor of the Department of Computer Control and Design Systems, Tomsk State University of Control Systems and Radioelectronics.

Tel.: +7-3822-41-39-15

E-mail: dmitriewvm@gmail.com 